\title{
Pressure changes after balloon distension of the colon wall in diverticular disease
}

\author{
A N SMITH, ${ }^{*}$ J SHEPHERD, $\dagger$ AND M A EASTWOOD \\ From the Gastrointestinal Unit and Departments of Clinical Surgery and Medicine, University of Edinburgh \\ and Western General Hospital, Edinburgh
}

SUMMARY Balloon distension of the distal colon in diverticular disease does not produce the pressure change in response to increasing volumes that occurs in normal subjects. This phenomenon, though modified at first by resection, is not abolished by resection nor by myotomy or bran. This adaptive quality of the wall of the colon to balloon distension possibly reflects a structural change in its wall, as the phenomenon was present in the colon in diverticular disease in vitro as well as in vivo.

The muscle of the large intestine is capable of producing a raised intraluminal pressure in diverticular disease. ${ }^{12}$ The force created may have a critical role in extruding the diverticulum. Furthermore, the reduction of the pressure appears to be beneficial in that symptoms become less and complications may become fewer. ${ }^{3}$ A paradox exists, however, in that balloon distension of the colon in diverticular disease ${ }^{4}$ produces a premature relaxation of the colonic wall indicating that it has developed characteristics which suggest reduction in its inherent strength. This phenomenon has been examined in normal subjects and in patients with diverticular disease with and without symptoms. The effects of treatment by cereal fibre and operations such as resection or myotomy which lower the intraluminal pressure" are also assessed.

\section{Methods}

Normal subjects and patients with diverticular disease before resection and myotomy were examined by passing an open-ended tube and large balloon system, similar to that of Parks," as far as the rectosigmoid junction. The balloon was attached to a triple lumen tube used for measuring intraluminal pressure and allowed inflation of the balloon. This was done in $20 \mathrm{ml}$ increments over the range of $20-200 \mathrm{~cm} \mathrm{H}_{2} \mathrm{O}$ pressure and the change in the balloon pressure was measured

*Address for reprint requests: Mr A N Smith, Department of Clinical Surgery, Western General Hospital, Crewe Road, Edinburgh EH4 2XU.

t Department of Surgery. University of Tasmania.

Received for publication 23 March 1981 graphically by attachment to a pressure transducer activating a preamplifier and linked penwriting system. The change in the inserted balloon pressure reflected the tension in the wall of the colon rather than the distensibility of the balloon itself. This could be deduced from pressure/volume curves for balloon distension in vitro to the point short of rupture: a very low pressure was established in the balloon at first, which differed from the pressure curve established when the balloon was placed within the colon of normal subjects. The pressure in vitro later rose to become similar to those obtained in the colon of normal subjects over the range $120-180 \mathrm{ml} \mathrm{H}_{2} \mathrm{O}$ as the distending volume (Fig. 1). Above this figure (at $200 \mathrm{ml}$ ) the balloon finally ruptured in vitro, though not necessarily in vivo because of the support of the colonic wall. These observations suggested that, at the low or mid-part of the curve, the response of the balloon reflected the contribution of the muscle of the colon. As the reactions in diverticular disease show a failure to maintain pressure even in the 'normal range', this could be considered as representing a weak response of the supporting wall of the colon, as was observed by Parks and Connell. ${ }^{4}$ Measurement was made of the point where the graph 'plateaued' and this was considered the critical point of pressure change. Each subject was studied in duplicate and his critical pressure derived from the average of the two tests.

\section{Results}

Figure 1 shows in graphical form how a critical point is reached in the balloon pressure in a normal 


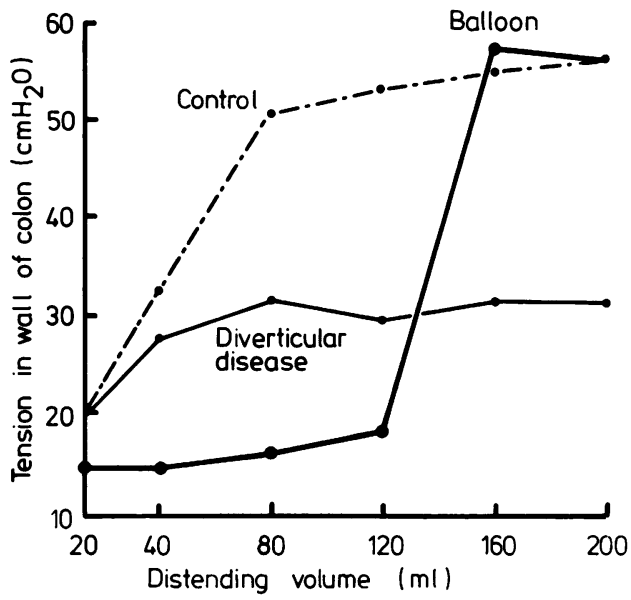

Fig. 1 A pressure volume curve after balloon distension in the colon in a normal subject and in one with diverticular disease, relating the tension in the colon wall in $\mathrm{cm}_{2} \mathrm{O}$ to serial distending volumes. The effect of distending the balloon in vitro is also shown and was followed by balloon rupture at $200 \mathrm{ml}$.
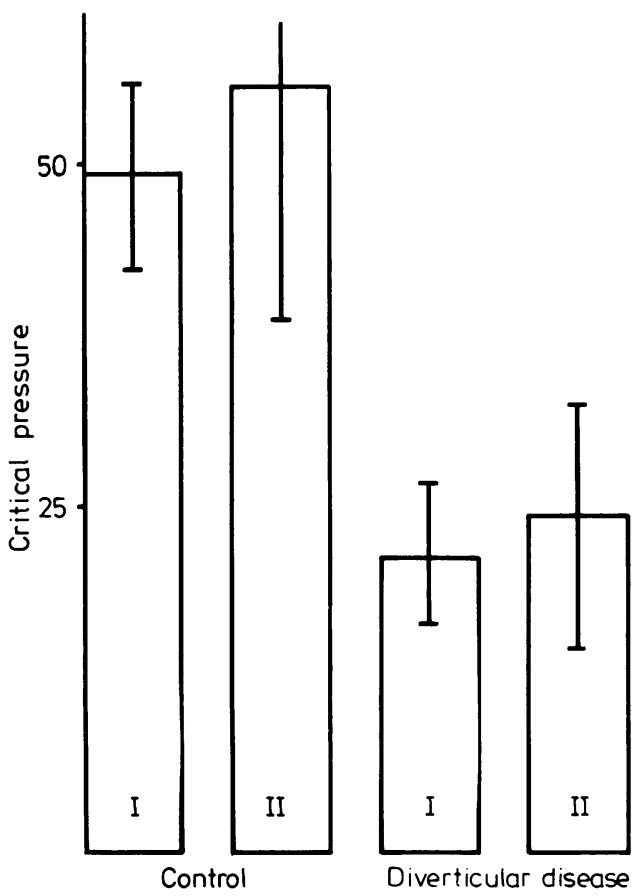

Fig. 2 Ten symptomless subjects ( $I$ ) and a similar number (II) with constipation are compared with 10 symptomless (I) diverticular disease patients and 10 symptomatic (II) cases; the results are expressed as means of the critical pressure $\pm S E$. subject at $55 \mathrm{~cm} \mathrm{H}_{2} \mathrm{O}$ pressure and in diverticular disease at $30 \mathrm{~cm} \mathrm{H}_{2} \mathrm{O}$ pressure, beyond which on serial distension little or no further increment of pressure takes place, and how in diverticular disease the pressure within the distending balloon may even fall with 'adaptation'. In Fig. 2 the mean critical pressure derived from such tracings is shown for 10 subjects with no symptoms (I) and 10 others (II) with no alimentary disease but with severe recent constipation; there was no significant difference in the critical pressure - that is, in the adaptation levels of the responses. In contrast 10 diverticular disease subjects (I) without symptoms (Fig. 2) and (II) 10 with pain and recent constipation had a significantly lower pressure at which the balloon pressure fell on distension by similar serial $20 \mathrm{ml}$ volumes $(\mathrm{P}<0 \cdot 001)$. Figure 3 shows the critical pressure in seven of the diverticular subjects who were to have resections performed. It will be seen that the critical pressure was the same when the subjects were examined in vivo and when their specimens were tested in vitro
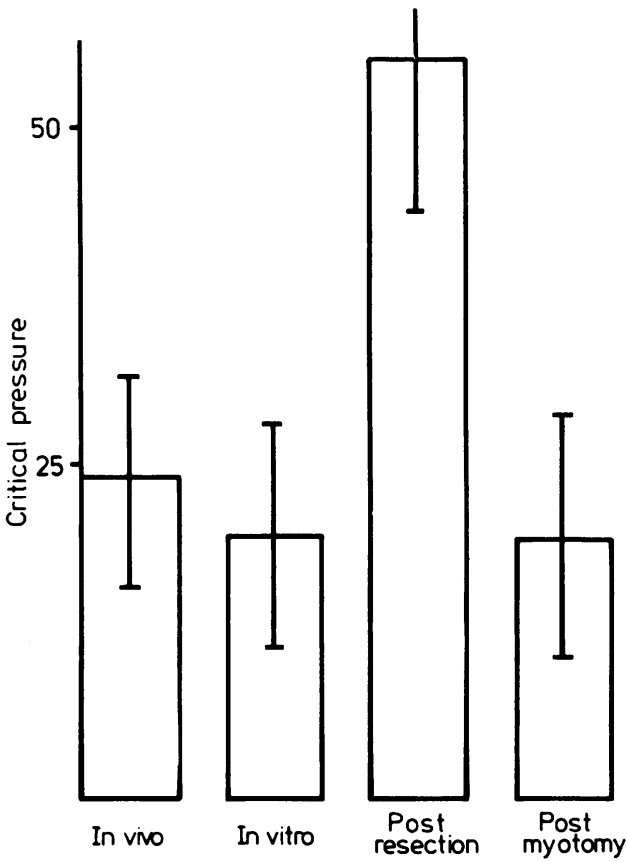

Fig. 3 Tests repeated in the same subjects; the mean critical pressure in seven subjects with diverticular disease examined in vivo compared with the critical pressure determined in vitro on resected specimens from the same subjects and again in vivo one month after resection. This is also compared with three subjects in whom the colonic circular muscle had been divided by the operation of colomyotomy. 
post-operatively $(\mathrm{P}<0 \cdot 001)$. When the same patients were examined a month after the resection, their critical pressure had risen to become similar to that of normal subjects. These responses were in marked contrast with three other subjects with diverticular disease who had had a myotomy performed, in whom the critical pressure remained low. When the same resection patients were tested at one year (Fig. 4) the critical pressure had fallen to the level of diverticular disease; there had been no change in the post-myotomy cases. Ten diverticular disease patients, both symptomatic and asymptomatic, and who had been treated with bran (Fig. 5), showed no significant change; nor did bran affect the properties of the colonic wall in normal subjects.

The responses to the distension at the rectal level were identical though less marked than at the rectosigmoid level.

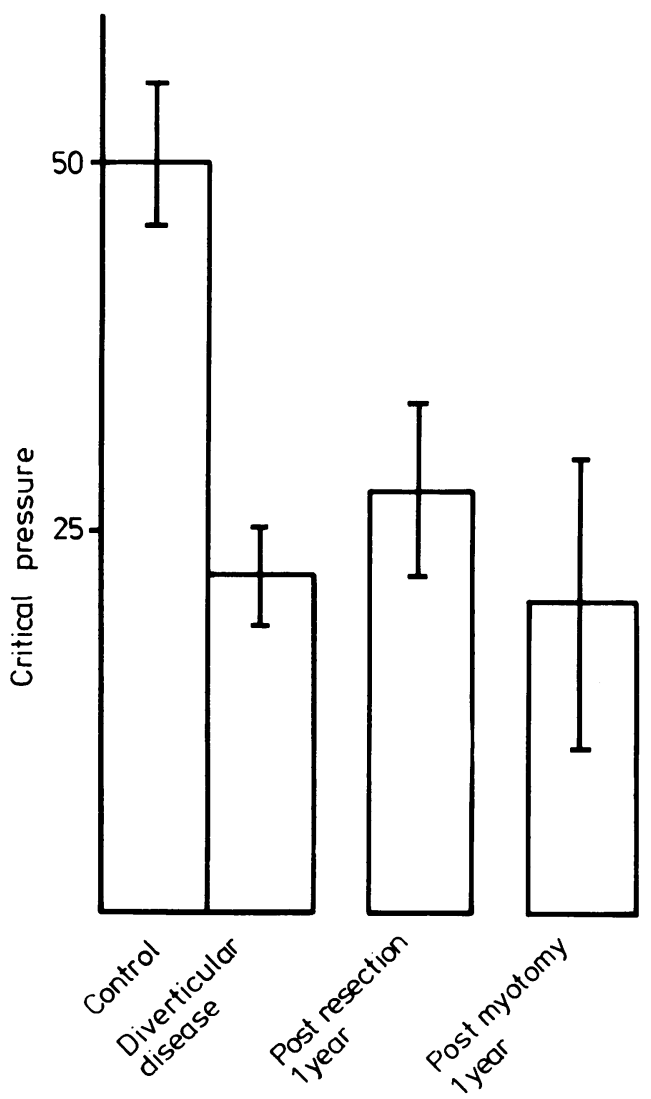

Fig. 4 The resection and myotomy studies were repeated one year later and are compared with the findings for normal subjects and for diverticular disease.

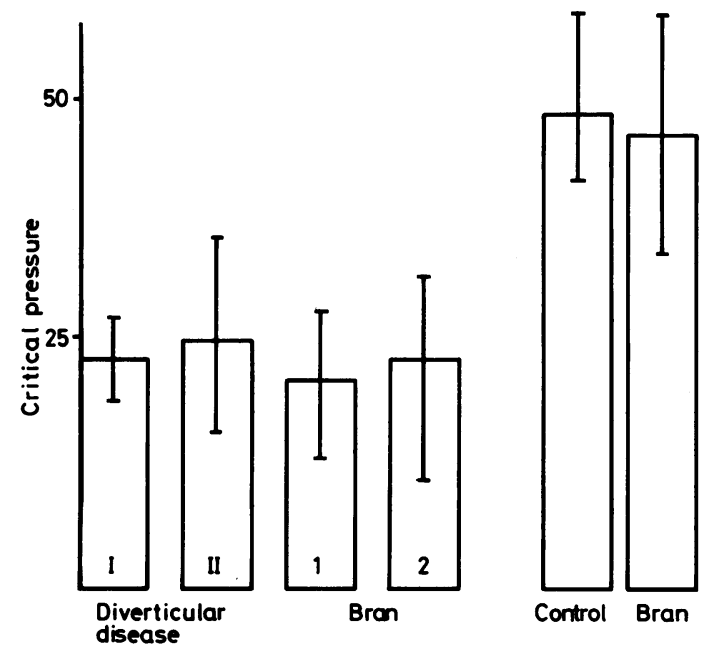

Fig. 5 The low critical pressure of diverticular disease is seen to be uninfluenced by bran, whether the diverticular disease subjects have (I) or have not (II) got symptoms. The higher critical pressure of normal subjects was uninfluenced by bran.

\section{Discussion}

Colonic intraluminal pressure in diverticular disease is raised, but only 'consistently' in patients with low faecal outputs and a delayed transit. ${ }^{7}$ Parks and Connell ${ }^{4}$ and Parks ${ }^{6}$ showed, however, that the wall of the bowel in diverticular disease, though capable of generating the raised pressure, is remarkably adaptive to distension and demonstrated how it yielded prematurely to colonic balloon distension compared with normal subjects. We have confirmed this and have shown that the phenomenon is present in vitro as well as in vivo, as it is present in tests in excised specimens as well as in subjects in vivo.

Resection of the pelvic colon which removes the diverticula does not appear to change the ready tendency of the colonic wall to relax, other than temporarily in the first month after operation. Myotomy, which lowers the intraluminal pressure, ${ }^{5}$ did not change the relaxation of the wall nor did the administration of bran, which also reduced the intraluminal pressure. ${ }^{8}$ It is unlikely, therefore, that bran influences the painful motor action of the pelvic colon in diverticular disease by an easier emptying of the distal bowel through a relaxation of its wall, as this change is already present in diverticular disease.

The fact that the phenomenon of relaxation after distension is present in diverticular disease and is not influenced by in vivo or in vitro testing or by treatment-be it by division or resection of the 
muscle or by bulk additives such as bran-suggests an intrinsic derangement of the arrangement of the collagen or muscle fibres of the colonic wall. Although a continually raised intraluminal pressure may be one factor which causes this change as well as extruding the diverticulum, it would appear that even if the pressure is reduced by treatment, the response to distension is not readily changed.

We are indebted to support from the Scottish Hospitals Endowment Research Trust Grant No. 418.

\section{References}

${ }^{1}$ Arfwidsson S. Pathogenesis of multiple diverticula of the sigmoid colon in diverticular disease. Acta Chir Scand 1964; suppl 342.
${ }^{2}$ Painter NS, Truelove SC. The intraluminal pressure patterns in diverticulosis of the colon. Gut 1964; 5: 201-3. ${ }^{3}$ Painter NS. Diverticular disease of the colon: a deficiency disease of western civilisation. London: Heinemann, 1975.

${ }^{4}$ Parks TG, Connell AM. Mobility studies in diverticular disease of the colon. Gut 1969; 10: 538-42.

${ }^{5}$ Attisha RP, Smith AN. Pressure activity of the colon and rectum in diverticular disease before and after sigmoid myotomy. Br J Surg 1969; 56: 891-4.

${ }^{6}$ Parks TG. Rectal and colonic studies after resection of the sigmoid for diverticular disease. Gut 1970; 11: 121-5.

'Eastwood MA, Smith AN, Brydon WG, Pritchard J. Colonic function in patients with diverticular disease. Lancet 1978; 1: 1811-2.

${ }^{8}$ Findlay JM, Smith AN, Mitchell WD, Anderson AJB, Eastwood MA. Effects of unprocessed bran on colon function in normal subjects and in diverticular disease. Lancet 1974; 1: 146-9. 